\title{
Las voces de los/as hijos/as de desaparecidos/as en Argentina: un género
}

y VICTORIA DAONA / IDES - CONICET / vicdaona@gmail.com

\section{A la memoria de Natalia Arińez ${ }^{1}$}

\section{Resumen}

Este texto propone leer como un género literario - propio de la literatura argentina de comienzos de siglo XXI- un corpus de novelas contemporáneas cuyos/as protagonistas y narradores/as son hijos/as de desaparecidos/as de la última dictadura militar. Para ello construye dos series literarias. Por un lado, la serie de "las novelas militantes» compuesta por: $L a$ casa de los conejos (2008) de Laura Alcoba, Soy un bravo piloto de la Nueva China (20II) de Ernesto Semán, Pequeños combatientes (2013) de Raquel Robles y Diario de una princesa montonera. II0\% Verdad (2012) de Mariana Eva Pérez. Por otro lado, la serie de "las novelas mutantes» conformada por: Los Topos (2008) de Félix Bruzzone, El espiritu de mis padres sigue subiendo en la lluvia (20II) de Patricio Pron y Una muchacha muy bella (20I3) de Julián López. Por último, analiza el libro de Marta Dillon, Aparecida (2015) que supondría una clausura de este nuevo género, al mismo tiempo que es el que permite pensarlo como tal.

Palabras clave: Hijos/as de desaparecidos/as • novelas • género $\cdot$ voces

\section{Abstract}

This text proposes to read like a literary genre - own of the Argentine literature of beginnings of S. XXI- a corpus of contemporary novels whose protagonists and narrators are children of disappeared of the last military dictatorship. The article proposes two literary series. On the one hand the series of «militant novels» composed by: La casa de los conejos (2008) by Laura Alcoba, Soy un bravo piloto de la Nueva China (20II) by Ernesto Semán, Pequeños combatientes (2013) by Raquel Robles and Diario de una princesa montonera. IIO \% verdad (2012) by Mariana Eva Pérez. On the other hand the series of «mutant novels» conformed by: Los Topos (2008) by Félix Bruzzone, El espiritu de mis padres sigue subiendo en la lluvia (20II) by Patricio Pron and Una muchacha muy bella (2013) by Julián López. Finally, it analyzes the book of Marta Dillon, Aparecida (2015) that would suppose a closure of this new genre, at the same time that is the one that allows to think about that.

Key words: Children of disappeared $\cdot$ novels $\cdot$ genre $•$ voices 


\section{Introducción}

Fecha de recepción: $24 / 2 / 2017$

En El género gauchesco. Un tratado sobre la patria (1988), Josefina Ludmer señala que la sustancia del género gauchesco es la relación entre voces oídas y palabras escritas. «Uso» $\mathrm{y}$ «emergencia» son las palabras que inician el tratado y tienen dos acepciones. El «uso» es tanto el uso literario de la voz como el uso económico y militar del cuerpo del gaucho. La «emergencia» es su surgimiento y también su necesidad urgente de uso. Para entender el género gauchesco es necesario entender cuál es el uso que la cultura letrada hace de la voz del gaucho para darle voz al gaucho; al mismo tiempo que es necesario entender cuál es el uso que el estado hace del cuerpo del gaucho. Pero también es necesario percibir la sutil diferencia entre el momento de emergencia del género y el momento en el que la repetición, la variación y la convención lo constituyen como tal dando cuenta de esa «necesidad urgente de uso» que se traduce en el creciente número de producciones con tonos y temas similares.

El momento de emergencia del género es tanto el momento de la transparencia como el de la paradoja puesto que sólo puede entenderse como tal una vez que el género ya está constituido. Ludmer localiza el inicio de la gauchesca en Los cielitos de Bartolomé Hidalgo y su clausura en La vuelta de Martín Fierro de José Hernández. Después del libro de Hernández, dirá, se abre una nueva cadena de usos que es la del uso del género para producir literatura en otros géneros que ya no son el de la poesía cantada, tal como es el caso de Don Segundo Sombras - la novela de Ricardo Güiraldes - y los cuentos de Borges sobre el tema. De esta manera, usos, emergencias y paradojas se definen también desde la movilidad temporal y en la diversidad de objetos literarios en tanto cada texto puede leerse desde y/o a través de un texto anterior o posterior conformando así series literarias siempre plausibles de ser leídas de otra manera.

Aunque no es Ludmer quien lee en la gauchesca «la voz nacional del gaucho», ${ }^{2}$ sí es ella la que permite pensar cómo y por qué el género gauchesco se constituye en el género literario de la patria. Y si bien no es posible homologar los textos de la gauchesca a las novelas de los/as hijos/as de desaparecidos/as en Argentina, los postulados de Ludmer permiten leer estas producciones desde una perspectiva que trasciende el tiempo presente en el que estas novelas son escritas y las ubica dentro del espesor literario nacional al mismo tiempo que habilitan nuevas lecturas en torno a un extenso corpus de novelas contemporáneas —las de los/as hijos/ as- que pueden leerse como figuraciones de una «voz nacional».

La hipótesis central de este artículo es que en la actualidad no sólo existe un gran número de novelas que entran dentro de la categorización de «novelas de hijos/as de desaparecidos/as», sino que además estas exponen tramas y temas cuyas complejidades representan el momento más acabado de la narrativa argentina en torno al pasado reciente. Los/as hijos/as no sólo son los/as herederos/as de aquella lucha de los años 70 iniciada por sus padres y madres; sino también los/as herederos/as de la lucha iniciada por Madres, Abuelas y otros familiares a fines de los años 70 desde los organismos de Derechos Humanos. Todos los textos sobre 
el período - previos o contemporáneos a los de los/as hijos/as — giran en torno a temas tales como: la violencia política, la militancia, el familismo, los derechos humanos y la construcción de las subjetividades. En las narrativas de este trabajo esos ejes aparecen en las tramas casi en su totalidad. ${ }^{3}$

Las novelas de los/as hijos/as reprochan al estado la desaparición de sus padres y madres; reconstruyen sus historias familiares y personales a la luz de los saldos provocados por el terrorismo de estado, formulan hipótesis en torno a la derrota de las organizaciones armadas de los 70, buscan formas simbólicas, subjetivas y políticas de reparación de las pérdidas y postulan narraciones posibles para las generaciones futuras en un afán por establecer un diálogo intergeneracional que no clausure la temática. En sus tramas está operando el concepto de «mediación» propuesto por Williams (I977) que da cuenta de los procesos activos a través de los cuales se pueden describir las relaciones entre una sociedad y el arte que produce en un momento determinado de su historia, al mismo tiempo que permite comprender cómo esas producciones interpretan a la vez que crean la realidad social en la que emergen. ${ }^{4}$

Williams señala que en sus usos más comunes la mediación hace referencia a «lo indirecto de la relación entre la experiencia y su composición» (I994:23), relación que en las novelas de los hijos/as resulta crucial para comprender la complejidad de las tramas. No porque exista una relación directa —o autobiográficaentre los/as escritores/as y aquello que narran, sino porque el uso de la voz de un/a hijo/a de desparecido/a habilita una poética particular que configura nuevos sentidos en torno al pasado de violencia política. Como sostiene Félix Bruzzone —autor de Los Topos (2008) — en una entrevista realizada en 20I4: «es interesante narrar desde la perspectiva de un hijo, independientemente de que yo sea o no sea un hijo de desaparecidos. Porque inevitablemente para un hijo de desaparecidos hay una condición que es la de no poder saber lo que pasó, hay como un vacío originario, que va a tener que ser llenado con algo y no necesariamente o casi nunca con la verdad. Entonces esa ausencia de verdad, esa ausencia de certezas, me parece súper productiva para contar una historia». ${ }^{5}$ Para Bruzzone el uso de la voz de los/as hijos/as de desaparecidos/as habilita la posibilidad de una poética particular que — en su caso — no busca fijarse en un relato autobiográfico referencial, sino por el contrario hacer estallar los sentidos de esa referencialidad.

Los postulados de Paul Ricoeur acerca de «la identidad narrativa» resultan productivos para entender esta diferenciación entre «lo autobiográfico» y lo «referencial». Para Ricoeur es fundamental entender que en el relato de ficción la identidad se conforma en el cruce entre las nociones de «mismidad» (asociado a lo «idem» o inmutable) y de «ipseidad» (que quiere decir propio y cuyo opuesto no es lo diferente si no lo extraño). Ricoeur pone especial énfasis en analizar la identidad narrativa desde su ipseidad que es lo que le permitirá ver cuál es la mutabilidad de esa identidad dentro de una estructura temporal a la vez que pensar qué es lo que puede llamarse «lo propio» de la identidad a la luz de sus cambios. Para Ricoeur, la poética de los relatos es la que permite hablar de una historia de 
vida de manera indirecta y sin que esté sujeta a la referencialidad de la realidad - como parámetro de verdad — y a la cronología de los hechos — como explicación causal del desencadenamiento de la trama.

Ahora bien, es importante decir que Ricoeur está pensando en narrativas en las que predomina el relato en tercera persona y en donde la voz de los personajes aparece mediatizada por la voz del narrador que organiza no sólo el desarrollo de la trama, sino también la trayectoria de ese personaje que es narrado, lo que lo coloca en una posición de subordinación en relación con lo que Ricoeur llama la mímesis de la acción. Pareciera que esta perspectiva ricoeuriana viene a esclarecer las zonas ambiguas en donde lo autobiográfico se confunde con lo ficcional, en tanto desde su perspectiva las fronteras que delimitan las figuras del/ a autor/a con el/la narrador/a y el personaje son claras. El problema aparece cuando los/ as escritores/as juegan con esas categorías y se aprovechan de la ambigüedad de los géneros discursivos para construir narraciones confusas. Lo que se complejiza aún más cuando la materia de la que tratan esos libros responden a temas de gran actualidad y sensibilidad social al momento de su emergencia y cuando quienes escriben se definen como afectados/as por dichas problemáticas, tal como es el caso de las novelas de los/as hijos/as de desaparecidos/as en Argentina.

A esto se refiere Mariana Eva Pérez - autora de Una princesa montonera. IIo\% Verdad (2012) - en una entrevista que el diario Página I2 le realiza en mayo de 20I2. En dicha entrevista, la periodista le pregunta a Pérez si encontró en su libro una forma de mezclar ficción y realidad, a lo que la autora responde que en la novela «está la realidad, están los sueños, y me interesó eso, que no se entienda bien... que sea confuso. Porque si no era todo con demasiada conciencia, quería que apareciera más ese mundo del inconsciente». ${ }^{6}$ Complejizando la posición de Pérez, en una entrevista para la Revista Ñ en agosto de 20I3, a la pregunta por el carácter autobiográfico de su novela, Julián López — escritor de Una muchacha muy bella (2013) - , responde: «en algún sentido es la historia ideal que quise tener: una madre desaparecida. Mi madre murió cuando era chico, pero de una muerte civil, me hubiera gustado una muerte con un sentido más social, esa que también te hace compartir valores y te aúna a otra gente». ${ }^{7}$ Luego, en otra entrevista sigue, «a mí no me tocó la desaparición en el seno familiar, pero sí a muchos de mis amigos y yo mismo crecí en la dictadura. Es también mi historia. Es una marca absoluta, innegable. Yo quería hablar de esto, de la memoria. Entonces hice una operación de apropiación. Lo siento como un derecho por haber pertenecido a esa generación» ${ }^{8}$ (López).

López — al igual que Bruzzone — elige la voz de un hijo de desaparecido para narrar porque le habilita una poética particular, un tono desde el cual contar una historia. Pero además en la respuesta de López aparece lo generacional como factor que posibilita la escritura; para él su cercanía a esos hijos/as de desaparecidos/as le permite «apropiarse» de un discurso que le pertenece por formar parte de esa generación afectada por el terrorismo de estado. En sus declaraciones se evidencia esa relación entre «experiencia y composición» a la que hace referencia Williams 
cuando habla de las mediaciones. Asimismo, sus declaraciones nos sitúan frente al problema de la legitimidad de la memoria. ¿Quiénes se arrogan el derecho a ser los/as dueños/as de esa memoria? Se trata de una pregunta difícil de responder aunque provocadora en su formulación por la tensión que existe tanto al interior del campo de los DD. HH., como del mundo académico y de la ciudadanía en general. Se trata, además, de una tensión constitutiva de las memorias y de los usos que pueden hacerse de las voces de los/as afectados/as directos/as, en este caso particular de las voces de los/as hijos/as, por lo que podríamos pensar que es también una tensión constitutiva del género de los/as hijos/as, puesto que como señala Jelin, "no hay una sola memoria, sino que hay "memorias contra memorias" (2002:6).

En las páginas que siguen veremos cómo se manifiestan esas mediaciones y esos usos de la voz en algunos libros de Laura Alcoba, Félix Bruzzone, Patricio Pron, Mariana Eva Pérez, Ernesto Semán, Julián López, Raquel Robles y Marta Dillón. Para hacerlo estableceré dos series narrativas: por un lado, la de «las novelas militantes», en las que incluyo los libros: La casa de los conejos (Alcoba 2008); Diario de una princesa montonera. IIo \% Verdad (Perez 20I2); Soy un bravo piloto de la nueva china (Semán 20II) y Pequeños combatientes (Robles 2013). Por otro lado, la de «las novelas mutantes», compuesta por: Los topos (Bruzzone 2008); El espiritu de mis padres sigue subiendo en la lluvia (Pron 20II) y Una muchacha muy bella (López 2013). Por último trabajaré con el libro de Marta Dillon, Aparecida (2015). El objetivo es que al final del texto cobre cuerpo la idea de entender a estas narraciones como un género particular cuya potencialidad poética y política radica en el uso que estas narraciones hacen de la voz de los/as hijos/as de desaparecidos/as.

\section{La irrupción de los/as hijos/as en las disputas por la memoria}

No es posible pensar las narrativas del pasado reciente en Argentina, sin atender a las disputas por la memoria que desde la década de 1970 mantienen tanto el Estado como los organismos de Derechos Humanos y algunas organizaciones formadas por familiares de militares. Son luchas por fijar, instaurar o rechazar diversos sentidos en torno al pasado; siempre situadas en el tiempo presente, que responden tanto a los avatares políticos y judiciales de los gobiernos de turno, así como también a procesos subjetivos e individuales de rememoración y/o reconstrucción de ese período histórico (Jelin 2002, 2010, 20II).

En el caso específico de las narraciones de hijos/as de desaparecidos/as, resulta necesario atender al proceso de creación y surgimiento de la organización H.I.J.o.s. Puesto que, si bien no todos/as los/as escritores/as ni los narradores/as de sus novelas son miembros de la agrupación, en todas las narraciones sobrevuela esa presencia. La aparición del organismo en la esfera social a mediados de la década de 1990 fue disruptiva en tanto supuso no solo una renovación generacional en relación con organismos como Madres y Abuelas, sino también una renovación en términos de acciones militantes y performáticas concretas. En «Hijos de desaparecidos. Entre la construcción de la política y la construcción de la memoria», Pablo Bonaldi analiza el surgimiento de la agrupación a la par que su incidencia 
en el terreno de los organismos de DD. HH. Para Bonaldi, desde el momento de su aparición a mediados de la década de 1990 la agrupación generó entre sus miembros un lazo de identidad colectiva muy fuerte. Y si bien entre los miembros existían intereses y expectativas diferentes con respecto a la agrupación, «más allá de esas diferencias este grupo compartía un conjunto de actitudes o disposiciones que los llevaba a preferir lo informal a lo formal, la transgresión a la disciplina, la improvisación a lo estructurado, lo homogéneo a las jerarquías» (I53).

Entre las posibilidades que la creación de la agrupación les abrió a los hijos, para Bonaldi, una de las más importantes en términos de tramitación de su historia personal, fue la de dar testimonio. Sin embargo, esa misma posibilidad con el correr de los años se transformó en temor a quedar atrapados en un círculo de dolor, lo que para Bonaldi sintetizaba la dificultad de construir una identidad social basada en un hecho traumático del pasado. H.I.J.O.s. va resignificar esto positivamente, puesto que a diferencia de los otros grupos generacionales que poblaban el terreno de los organismos de DD. HH., los hijos no buscaban sólo saber dónde estaban sus padres, sino también saber quiénes habían sido, lo que los convirtió «en portadores de preguntas, necesidades e inquietudes que los llevan a resignificar la figura de los desaparecidos» (I62).

Raquel Robles - autora de Pequeños combatientes (2013) y una de las fundadoras de H.I.J.O.s. - en 2014 escribe un artículo a propósito de los i9 años de la agrupación ${ }^{9}$ en el que reconstruye la trayectoria de la organización desde sus inicios dando cuenta de esa fuerte identificación colectiva que señalaba Bonaldi en 2006. Para Robles la creación de H.I.J.o.s. sólo puede entenderse como una historia de amor: "éramos unos enamorados, de los que no pueden dejar de mirarse a los ojos», dice. Fue ese amor colectivo el que les permitió iniciar una lucha en el terreno de los DD. HH. que se aunó con la de los organismos de Madres y Abuelas de Plaza de Mayo y que se legitimó en la Marcha de la Resistencia de 2002 en la que las madres les entregaron sus pañuelos a los/as hijos/as.

Para Robles ese acontecimiento significó «un traspaso generacional y una posta entregada a los más jóvenes» que daba cuenta de una lucha colectiva y compartida que se había iniciado con la militancia de sus padres y que ahora se resignificaba con los reclamos de verdad y justicia que exigían no sólo los organismos de DD. HH., sino también en términos simbólicos y políticos, los miembros vivos de esas familias desmembradas por el Terrorismo de Estado. En las palabras de Robles se explicita que la novedad que supuso la irrupción de la agrupación H.I.J.O.s. en el terreno de la acción política no se pensó nunca en términos disruptivos con relación a los otros organismos, sino como una irrupción que completaba al núcleo de familiares víctimas de la dictadura militar a la vez que evidenciaba de qué manera tenía lugar la transmisión generacional en el seno de la familia de los organismos de DD. HH. Lo que legitimaba la aparición de este nuevo actor político era el lazo de sangre que unía a los/as hijos no sólo con sus padres y madres desaparecidos/as, sino también con las abuelas — tanto Madres como Abuelas de Plaza de Mayo_- que reclamaban justicia desde fines de la década de I970. 
Contemporáneamente al surgimiento de la organización, los/as hijos/as (no sólo los miembros de la agrupación) comenzaron a intervenir también en el terreno artístico y cultural dando lugar a diferentes producciones que entre mediados de los años 90 y principios de los 2000 fueron preponderantemente audiovisuales. ${ }^{10}$ En su artículo «Órdenes de la memoria y desórdenes de la ficción», Ana Amado señalaba que el eje de estas primeras producciones - entre las que se destacan las películas Papá Iván (2000) de María Inés Roqué y Los Rubios (2003) de Albertina Carri- estaba puesto en las filiaciones y las genealogías fracturadas por la violencia política. Al final de su texto Amado llegaba a la misma conclusión que Bonaldi, puesto que para ella «los hijos no rompen con el pasado, sino que rompen con las formas en que se rompe con el pasado» (80) y aclaraba que se trata de «una flexión cultural de la memoria que hoy recodifica y en gran parte sustituye los mundos comprensivos de aquellos ańos» (80). Romper con las formas supuso renovar una estética que — cruzando a Bonaldi con Amado- estaba muy institucionalizada en los primeros organismos de DD. HH. — principalmente Madres y Abuelas - y que H.I.J.o.s. buscó reformular pero no contradecir. Tanto para Amado como para Bonaldi este cruce puede entenderse a partir de una mirada generacional que asocia los formatos tradicionales a la de los viejos pertenecientes al campo y los formatos rupturistas a los recién llegados.

En su libro Los prisioneros de la torre de babel. Politica, relatos y jóvenes en la postdictadura (20II), Elsa Drucaroff se ocupa de esa mirada generacional en lo que denomina «la nueva narrativa argentina». Allí analiza las producciones de quienes fueron jóvenes durante los años 80 y 90 sin discriminar entre hijos/as de desaparecidos/as o no. Se trata, dice, de una narrativa «socarrona» en tanto su tono no es solemne o serio, sino más bien irónico, lo que para ella está estrechamente ligado a la conmoción que supuso el Golpe de Estado de 1976.

Estamos ante una narrativa construida en un doble movimiento respecto de 1976 [sostiene]: distancia irreductible si es el final de una etapa, pero presencia ineludible porque es el comienzo de ésta: un imaginario atravesado por un presente acuciante y sin salida que cada vez pide más atención, pero sellado por el pasado traumático, por un conflicto que atormenta como sombra, fantasma, la sociedad en la que estos escritores crecieron. (27)

En la nueva narrativa argentina, 1976 es un punto de partida que se manifiesta a través de variaciones formales, temáticas, elípticas y/o fantasmáticas.

Por otra parte, Drucaroff critica los discursos institucionales de los organismos de DD. HH. en tanto considera que estos han colaborado a pensar el período desde el horror de los crímenes de lesa humanidad, al mismo tiempo que han construido un tabú en torno a lo que ella denomina «la fiesta militante de los años 70" y "el heroísmo guerrillero» (195). Y si bien resalta las acciones reivindicativas de los gobiernos de Néstor Kirchner (2003-2007) y Cristina Fernández (2007-20I5), considera que ninguno de estos sucesos ha logrado aún generar una reflexión libre sobre la lucha política de los años 60 y 70 en Argentina. Ni 
siquiera la agrupación H.I.J.o.s. dice «escapa del tabú del enfrentamiento y no se siente autorizada plenamente a enfrentar el "fue por nada" y proteger y homenajear nuestros recuerdos y la verdad, declarando que sus padres quisieron instaurar el socialismo en el país, y que una parte de ellos tomó el fusil para lograrlo» (196).

Si bien es posible retrucar esta última afirmación de Drucaroff principalmente a partir de los trabajos de Rossana Nofal sobre el género testimonial (Nofal 20ı,, 20I5): ${ }^{11}$ simplemente diré que desde que se publica Los prisioneros de la torre en 2OII hasta ahora, sí han aparecido narraciones de hijos/as de desaparecidos/as que tematizan el fervor y el entusiasmo de la militancia armada y el heroísmo guerrillero de los ańos 70 y que son esos textos los que conforman el corpus de trabajo de este artículo. Pero, además, resulta importante resaltar que fueron aquellas acciones reivindicativas de los gobiernos de Néstor Kirchner y Cristina Fernández de Kirchner las que habilitaron y legitimaron desde el estado el uso de las voces de los/as hijos/as - y de otros afectados/as directos/as - en tanto supusieron un aval a las políticas de memoria impulsadas durante sus presidencias. Habrá que esperar para saber qué pasará en los próximos años respecto de los usos y las legitimidades en tanto a partir de diciembre de 2015 las políticas estatales en torno a la memoria del pasado reciente en Argentina han cambiado su sesgo ideológico.

\section{Las novelas militantes}

Llamo novelas militantes a aquellas que en sus tramas retoman, mencionan y en algunos casos realizan actividades militantes dentro los organismos de DD. HH. La idea de la «militancia» no supone que todas estas novelas adhieran a esas luchas, pero sí que las acompañen a pesar de las diferencias o críticas que puedan realizar. La serie está compuesta por: La casa de los conejos (2008) de Laura Alcoba, Soy un bravo piloto de la Nueva China (20II) de Ernesto Semán, Pequeños combatientes (20I3) de Raquel Robles y Diario de una princesa montonera. IIo \% Verdad (2012) de Mariana Eva Pérez.

Estas cuatro novelas recuperan escenas de infancia que están atravesadas por la militancia armada de los años 70 y por el terrorismo de estado que - en tres de los cuatro relatos - reprime y desaparece a los padres. En todos los casos, la irrupción de la violencia — asociada a un acontecimiento traumático sucedido en la infancia - supone para las/os narradoras/es revisitar esos acontecimientos desde la adultez y a partir de allí intentar esbozar interpretaciones en torno a lo que sucedió y a cómo cada una/o tramitó esa historia personal. Las múltiples temporalidades que aparecen plasmadas en estas novelas dan cuenta de los procesos de elaboración de las memorias que cada narrador/a realiza de acuerdo no sólo a los diferentes estadios que asumieron las luchas por la memoria, sino también de acuerdo a las diferentes etapas de sus vidas desde las que deciden escribir estas historias.

En el caso de La casa de los conejos (Alcoba) los motivos que impulsan a Laura — la narradora - a escribir responden a los motivos clásicos del testimonio. La narradora toma la palabra para romper el silencio y contar su experiencia infantil en una casa operativa de Montoneros impulsada por una visita que realiza a la 
Argentina en 2003 con su hija, cuando vuelve por primera vez a esa casa que habitó en su infancia. Emprende, entonces, un trabajo de rememoración que le permite construir una interpretación del pasado que puede transmitirse a las generaciones venideras. Dos son los momentos que se identifican en el texto: el presente de la enunciación y el presente del enunciado que se distinguen por la mención de las fechas y el cambio de registro con el que se escribe, al mismo tiempo que se confunden en el proceso de elaboración del pasado.

Tanto en el prólogo como en el epílogo escuchamos la voz de Laura, adulta, exponiendo los motivos que impulsaron su escritura, interpretando los sucesos del pasado y condenando la delación que provocó la caída de la casa y la muerte de quienes estaban allí. El cuerpo del texto, en cambio, se escribe con la voz infantil de Laura que observa y vive en esa casa operativa sin hacer demasiadas preguntas puesto que está advertida del peligro que supone hablar. La presencia de esas dos voces — la de la niña y la de la adulta - hace que en la novela las preguntas del pasado se completen en el presente de la enunciación y se conjuguen con el deseo futuro de intervenir en la transmisión generacional. Pasado, presente y futuro se conjugan en esa temporalidad compleja que — señala Jelin (2002) — es la que moldea y prefigura los trabajos de la memoria.

En Soy un bravo piloto de la Nueva China (Semán), Rubén —el narradorbusca romper con la imagen que su madre ha construido y transmitido de su padre desde que este desapareció. La figura del camarada Abdela está mediada por la palabra de una madre que está a punto de morir. Rubén necesita separarse de esa mediación y encontrar una imagen propia que le permita, al mismo tiempo que evitar la pérdida del relato ante la inminencia de la muerte materna, construir un relato de familia que pueda transmitirse a las nuevas generaciones. Se trata de una doble búsqueda que supone alejarse de lo estatuido en la voz de su madre y acercarse a una zona de su memoria que había quedado guardada en un escáner imaginario. La voz de Abdela en la novela es una construcción que hace Rubén con los retazos de una memoria que en parte ha heredado, en parte conoce y en parte imagina.

En la novela de Semán la temporalidad es compleja puesto que si bien esta se escribe en un presente en el que Rubén ha quedado huérfano y está por ser padre, será ante estas nuevas circunstancias que él revisita su pasado a través de lo que conoce y de los relatos que le transmitió su madre y además construye un espacio llamado La Isla que funciona como una «Cámara Gesell» en donde conviven su padre y su represor y en donde Rubén —adulto - los observa. A diferencia de la novela de Alcoba, aquí no existe una distinción que marque el presente y el pasado de la enunciación. Por el contrario, el pasado se cuela constantemente en el relato del tiempo presente. Lo que sí comparte esta novela con la de Alcoba es el hecho de entender la transmisión hacia las nuevas generaciones como una posibilidad que habilita y merece la reconstrucción de estos relatos del pasado.

En Diario de una princesa montonera (Pérez), el presente es el tiempo de la narración. Las historias que M. relata son «vistas del pasado» (Sarlo) que se hacen 
desde ese presente en el que ella se siente legitimada para hablar de una manera irreverente sobre «el temita» por su condición de «hiji» y por su militancia en organismos de DD. HH. En este aspecto no es menor que M. se llame a sí misma Princesa Montonera en un afán por marcar su linaje y reconstruya el itinerario que la llevó a alcanzar ese título nobiliario. La legitimidad que M. se arroga no está dada solamente por su condición de afectada directa, sino también por esa condición de «emprendedora de la memoria» que la lleva a vivir «una vida Ioo \% atravesada por el terrorismo de estado» (39).

En cuanto a la relación que ella establece con esas «vistas del pasado» (Sarlo), M., al igual que Rubén, también necesita romper con lo estatuido de las formas. No le alcanzan las anécdotas de su abuela paterna, ni el discurso oficial de Abuelas de Plaza de Mayo. M. necesita salir de los marcos institucionales del familismo para encontrarse con un relato de sus padres que sea menos solemne, por eso prefiere las fotos de su papá rockstar y las cartas de su mamá a un ex novio, porque es en esos lugares en donde sus padres dejan de ser los de las fotografías del cartel de los organismos y se convierten en personas con una vida más allá del terrorismo de estado. Tanto Rubén como M. buscan nuevas palabras para apropiarse de un relato que no sólo es heredado, sino también público. Necesitan generar espacios de intimidad en donde sus padres no sean sólo héroes o víctimas, sino padres y madres en una cotidianeidad que se ha perdido en el caso de Rubén o desconocen, tal como es el caso de $\mathrm{M}$.

Si Rubén y M. son adultos cuando escriben y Laura necesita recuperar desde su adultez la voz de niña para relatar aquellos años de infancia en una casa operativa de Montoneros; en Pequeños combatientes (Robles), el tiempo del enunciado son esos años que van entre el secuestro de los padres y la Guerra de Malvinas. La narración termina después de la Guerra con la publicación de las listas de algunos nombres de muertos por la dictadura militar. En esa narración, el pasado es el tiempo de los padres y el de la vida en familia y el futuro se avizora recién hacía el final de la novela, cuando la narradora comprende que «tal vez esa vida que estábamos viviendo no fuera un mientras tanto sino un para siempre» (I46).

En la novela la narradora asume como propio el discurso de la militancia de sus padres y desde allí emprende un duelo que se parece más a una resistencia clandestina. La niña se empeña en no perder la doctrina militante que la une no sólo a sus padres, sino también a todos esos compañeros que no se sabe dónde están y a una Revolución que «iba a hacernos muy felices a todos, porque si no, la verdad es que las cosas que pasaban eran como para acostarse en las vías del tren» (I23). Será esa misma convicción en la Revolución la que al final del libro le permitirá tender puentes con esas figuras desaparecidas en el fragor de una lucha. «De todos modos, qué otra cosa podíamos hacer» (I52), dirá la narradora en un afán por comprender sin reprochar las elecciones de sus padres y ese destino final.

El diálogo intergeneracional es uno de los pilares sobre los que se organizan estas cuatro narraciones. En las novelas las/os narradoras/as establecen vínculos con las generaciones que los preceden — principalmente con la de sus abuelas- 
y buscan construir puentes que las/os acerquen a las generaciones que vendrán. En el caso de la novela de Alcoba, la presencia de Chicha Mariani es fundamental para conectarse con esa historia pasada y el deseo de darle a conocer a sus hijos todo aquello, lo que impulsa y motiva su escritura. Rubén también se posiciona entre sus padres y su hijo por venir y su relato se convierte en un eslabón fundamental para que la historia de los orígenes no se pierda tras la muerte de su madre. En cuanto a M. si bien en su narración ella no proyecta hacia el futuro, sí establece fuertes vínculos con la generación de las abuelas y se llama a sí misma «la nińa-vieja criada por los abuelos» (I65). Por su parte, la narradora de la novela de Robles también se posiciona como tercera generación y desde allí anhela un futuro en el que la Revolución los haga muy felices.

Las cuatro novelas vuelven a la infancia para hablar de la historia de sus padres e incluirse ellas/os en esas genealogías familiares que se fracturaron siendo niños y niñas, puesto que como sostienen Bonaldi y Amado, estos hijos no sólo buscan dar a conocer lo sucedido, sino también saber quiénes fueron sus padres. Rubén, M. y la narradora, buscan explicaciones, preguntan, se arman relatos en donde esa catástrofe se gestiona porque resulta necesario. Los tres indagan en ese espacio de la experiencia, el que es propio y el que fue transmitido y desde allí pueden esbozar un horizonte de expectativas en donde la desaparición de sus padres - aunque dolorosa - produce sentido para sus vidas. En el caso de la novela de Alcoba, si bien ella no pierde a sus padres, el hecho de saber que todas las personas con las que vivió desaparecieron por culpa de la delación de un compañero la impulsa a romper el silencio y a escribir su versión de la historia. Las/os cuatro narradoras/es manifiestan la necesidad de inscribir esas pérdidas dentro de un relato que sea narrable hacia otros y pueda transmitirse. Pero también manifiestan la necesidad de no fijar esos sentidos en una zona de clausura, por eso hacia el final de las novelas todos tienen nuevas hipótesis en torno a lo sucedido.

Las novelas de esta serie establecen fuertes vínculos con los organismos de DD. HH., sea tanto para adherir a sus consignas como para cuestionarlas. En el caso de la novela de Alcoba, esa posición se evidencia en ese eslabón generacional que une a Laura con las abuelas y los militantes que fueron sus padres en la denuncia de aquellos crímenes cometidos por la dictadura militar, a la vez que en la necesidad de dar a conocer esa historia a las generaciones futuras. Lo «militante» en la novela de Semán se evidencia en la idealización que del camarada Abdela hace Rubén a pesar del enojo que tiene con él por haber antepuesto la revolución a la familia. Pero además, esa posición se hace visible en el contraste entre las acciones de Rubén y las del hijo del represor que desapareció a Abdela, puesto que mientras uno mata al padre, el otro logra reconciliarse con el recuerdo del suyo en pos de armar un linaje familiar.

En cuanto a la Princesa, si bien en su diario cuestiona constantemente las políticas de los organismos — sean Abuelas o H.I.J.o.s. — esos cuestionamientos los hace a partir de la legitimidad que siente al ser hija de desaparecidos y nieta de una de las abuelas que dirige la organización. Por último, la novela de Robles 
asume como propio el discurso militante de sus padres a la par que irá construyendo un nuevo relato en el que la Revolución es una posibilidad de futuro que resignifica aquella lucha a la vez que transforma esos ideales en una nueva posibilidad que cobra fuerza en la voz de los/as hijos/as. Pequeños combatientes (Robles) transforma el discurso de los padres para continuarlo, pero no para transgredirlo, como sí lo hacen las novelas de la próxima serie.

\section{Las novelas mutantes}

En la presentación de Los topos (Bruzzone), en mayo de 2009, Nicolás Prividera - director de cine e hijo de desaparecidos - establecía una clasificación entre las distintas posiciones que los/as hijos/as de desaparecidos/as tomaban frente a la historia de sus padres. "Podríamos decir — sostenía Prividera— que si por un lado hay hijos «replicantes» (que repiten las inflexiones fantasmáticas de la voz del padre), y por el otro lado hay hijos «frankensteinianos» (que pretenden escapar de ese mandato negándose a su destino hamletiano de reclamar simbólica venganza), entre ambos están los hijos «mutantes» (que asumen su origen, pero no quedan presos de él)».

Para él, esa condición mutante ponía en el centro de la escena la «inadecuación» de los/as hijos/as de desaparecidos/as y la necesidad de buscar respuestas a esa historia en el presente y en el futuro, más que en el pasado.

Esa mutación [sostenía] produce obras abiertas, imperfectas, y de múltiples caras (aunque no escapen a un involuntario "espíritu de época») cuyo aire familiar es su ofendido, pero nunca humillado desamparo, que sabe que esa intemperie puede ser también una condición de posibilidad, para construir desde esa mirada un inquebrantable mundo propio.

Entre el espíritu de época — marcado por el surgimiento de H.I.J.O.s - y el mundo propio - como posibilidad de construir un relato diferente al de los organismos aunque no completamente rupturista—, la condición «mutante» de ciertas obras hacía para Prividera «de la diferencia una forma y una formulación».

En este trabajo tomo la idea de novelas «mutantes» para hablar de aquellas novelas que plantean diferentes modos de abordar esa condición de hijo/a de desaparecido/a no sólo desde las estéticas, sino también desde el contenido de las tramas. Esta serie está compuesta por Los Topos de Félix Bruzzone, El espiritu de mis padres sigue subiendo en la lluvia de Patricio Pron y Una muchacha muy bella de Julián López. Las tres novelas construyen anécdotas y narradores que no se asimilan entre sí, pero tampoco lo hacen con otras novelas de hijos/as. Son relatos mutantes que «hacen de la diferencia una forma y una formulación» (Prividera).

En el caso de la novela de Bruzzone la diferencia está dada por las transformaciones que va sufriendo el narrador a lo largo de la novela, quien pasa de ser un hijo de desaparecidos criado por su abuela a convertirse en una travesti que termina siendo secuestrada por su pareja, de quien sospecha que fue un torturador durante la dictadura. Entre un estado y otro, el narrador irá atravesando 
diferentes pérdidas que lo llevarán a encontrarse solo, indocumentado y sin ningún tipo de anclaje en la realidad más allá de la fantasía de encontrar a Maira, una travesti desaparecida de quien el narrador está enamorado y de quien supone que puede ser su hermano nacido en cautiverio.

En el caso de la novela de Pron, el narrador es un joven argentino que vive en Alemania en donde tiene una beca para realizar un doctorado. La novela comienza con la mención a la pérdida de la memoria que al narrador le provocan las pastillas antidepresivas que le receta el psiquiatra alemán y que no sólo lo mantienen como anestesiado en el presente, sino que además le permiten mantenerse alejado de los recuerdos del pasado. Ese estado comienza a fisurarse cuando al narrador le avisan que su padre ha sido internado en Argentina y su vida se encuentra en peligro. Al regresar a su país y ver a su padre casi al borde de la muerte, el narrador comenzará a recordar aquellas cosas que lograba mantener silenciadas con las pastillas y que tienen que ver con la militancia de sus padres y con el hecho de indagar cómo esa militancia repercutió en la conformación de su subjetividad.

En cuanto a la novela de López, Una muchacha muy bella, el narrador es un hijo que reniega de su condición pública: «no puedo haber sobrevivido a esa muchacha bella y saber todo lo que no sé. No puedo ser el hijo de esa mujer menor que yo ante el abismo. No lo aguanto» (I52). La filiación con su madre es algo que pertenece a su completa intimidad, algo casi secreto que encuentra sentido - sorprendentemente para él— en un hábito tan cotidiano como tomar té. Su madre forma parte de una cotidianeidad de salchichas con puré en donde la militancia queda limitada a los momentos en que ella se encuentra ausente. El día a día de su infancia no es el de las doctrinas, ni el de las armas, sino el de las postales de Holanda y el humo del tabaco. Por eso la ausencia no puede explicarse o justificarse en la convicción de unas ideas que el narrador desconoce: «no hay ningún hombre nuevo volviendo de entre los muertos» (I5O) dice y en esa frase rompe por completo con la generación de su madre.

En los tres casos estos hijos esquivan o cuestionan el accionar de sus padres a la vez que construyen una posición que pretende estar desligada de ese pasado familiar. Sin embargo, ninguno logra desligarse por completo de esa genealogía, en tanto las marcas del pasado vuelven en el presente asumiendo distintas formas. En el caso de la novela de Bruzzone, el narrador no indaga en las huellas que dejó en su vida la violencia política, sin embargo, las mismas aparecen en el presente de la narración de manera casi involuntaria. De hecho, la novela termina con el narrador secuestrado en las montañas de Bariloche sin nadie que sepa de su paradero, tal como desapareció su madre, su padre y todos los demás desaparecidos por el terrorismo de estado. En la novela de Pron, el narrador creía mantenerse distante de aquella historia de los años 70, sin embargo, su regreso al país, la comprobación de que su padre podría morir y el descubrimiento de la investigación que estaba realizando su padre antes de enfermarse lo conectan y lo reconcilian con esa parte de su pasado. Por su parte, en Una muchacha muy bella (López), el narrador escribe sobre su propia cotidianeidad y sobre cómo esa rutina sostenida 
por hábitos que creía propios y sin linaje, se le revelaron cargados de su historia pasada y familiar.

El pasado de aquellos ańos de violencia aparece en el presente de las enunciaciones de los narradores, lo que permite dar cuenta de que - como sostiene Jelin - los trabajos de la memoria son procesos subjetivos que están anclados en experiencias y en marcas simbólicas y materiales que se activan en el presente y que no pueden pensarse por fuera de esa temporalidad compleja que supone recordar desde un presente el tiempo pasado (Jelin 2002). En cuanto a cómo los narradores se conectan, en los tres casos de formas casi involuntarias, con sus historias familiares, Jaques Hassoun en Los contrabandistas de la memoria, sostiene que el hecho de ser rebeldes o escépticos a lo que nos ha sido legado «no excluye que nuestra vida sea más o menos deudora de eso, de ese conjunto que se extiende desde los hábitos alimentarios a los ideales más elevados, los más sublimes, y que han constituido el patrimonio de quienes nos han precedido» (I5-I6).

En estas novelas los narradores - aunque lo intentan - no pueden desligarse por completo de sus genealogías familiares. Aun a pesar de travestirse para convertirse en otra, como el narrador de Los Topos; de irse del país y consumir ansiolíticos como el narrador en El espiritu de mis padres sigue subiendo en la lluvia, o de renegar de esa historia materna que lo excluye como en el caso del narrador de Una muchacha muy bella. Esto da cuenta de que en todos los casos tienen lugar los procesos de transmisión de las historias familiares, ya sea a través del silencio, la omisión o la narración; y que lo que varían son las formas de apropiación de esos relatos. Lo interesante es que tanto en la novela de Bruzzone como en la de López no se vislumbran procesos de transmisión de esas historias a futuro. De hecho, ambos narradores se colocan al final de esas genealogías y no pueden proyectarse hacia adelante, lo que evidencia las fracturas que en esos entramados familiares dejó el terrorismo de estado. En cuanto a la novela de Pron, en cambio, el narrador se asegura la transmisión de esa historia a través de la escritura de su novela.

Las cuestiones de género también aparecen trabajadas en estas novelas de maneras diferentes. Los Topos rompe con la heterosexualidad predominante en las narraciones sobre los años 70 en Argentina, pone al travestismo en el centro de la escena y lo erige como una identidad que tanto Maira como el narrador eligen para conectarse con su historia pasada y con sus afectos. Recordemos que Maira se hace travesti para que su hermana mujer, que nació en cautiverio, pueda reconocerse en ella y así descubrir su verdadera identidad y que el narrador decide travestirse para vengar la desaparición de Maira, de quien sospecha que es su hermano nacido en cautiverio. Lo desafiante de Los Topos es que si bien esta novela puede leerse desde una perspectiva «queer» que de acuerdo a Cecilia Sosa cuestionaría la legitimidad que da el familismo a los relatos del pasado dictatorial; el narrador no puede escapar del familismo de ese relato. Y aunque no busca posicionarse como una voz legitimada, sino por el contrario, siempre se aparta de la posición de la agrupación H.I.J.o.s., es casualmente esa condición de hijo de desaparecidos la que lo habilita a cuestionar el discurso de los DD. HH., a destruir 
cualquier tipo de continuidad o transmisión de su historia y a travestirse como forma de acercarse a sus afectos e intentar vengarlos para así lograr que se haga justicia. En esta novela lo «queer» no aparece para cuestionar ese familismo, sino para exacerbarlo en tanto evidencia que para el narrador transformarse en otra le permite acercarse a esa historia familiar de la que casi no habla en la novela, a la vez que da cuenta de la imposibilidad que encuentra para poder revertir esa situación, puesto que en la narración nunca logra vengar a Maira, sino que por el contrario queda preso de su torturador y por ende de ese pasado familiar.

Una muchacha muy bella plantea desde su título la construcción de una mujer que se vuelve bella ante la mirada de un hijo que sólo quiere recordar de su madre el tiempo en que estuvieron juntos sin detenerse a pensar en las actividades que ella realizaba mientras él no estaba presente. La belleza de la madre revela la construcción de un estereotipo de mujer que el narrador quisiera conservar, aunque es el accionar de su propia madre el que lo contradice no sólo al ser militante de una organización armada, sino también madre soltera dentro de una organización guerrillera como el Ejército Revolucionario del Pueblo (ERP) que se caracterizó por sus doctrinas conservadoras en torno a las concepciones de familia. La belleza de su madre radica en esa transgresión que la vuelve lejana. La misma transgresión que luego manifiestan las adolescentes cartoneras que cierran la novela mientras se ríen del narrador sin intentar responderle de qué se ríen y tampoco sin intentar comprenderlo.

En estas novelas las categorías de género son cuestionadas en tanto resultan insuficientes para pensar en los procesos de conformación de los sujetos y las identidades tal como sucede en la novela de Bruzzone, o resultan indescifrables como lo muestra la novela de López en cuyo caso el narrador intenta construir un estereotipo femenino clásico que es refutado por los propios personajes femeninos de la novela. Lo interesante es que a partir de estos posicionamientos en torno al género los narradores pueden pensarse en relación con sus historias familiares, al lugar que ocupan en esas genealogías y a los procesos de transmisión o no transmisión de esos linajes.

En cuanto a la condición mutante de estas novelas (Prividera), creo que la misma se manifiesta más plenamente en esa inadecuación que Prividera define como característica de todos los/as hijos/as de desaparecidos/as y que en estos relatos aparece reflejada en la posición que asumen los narradores frente a la relación que tienen sus historias personales con la violencia política de los años 70 y el terrorismo de estado. En los tres casos, el hecho de ser hijos de quienes estuvieron involucrados en la lucha armada no resulta cómodo ni agradable para los narradores. Por el contrario, los tres buscan construirse a sí mismos en oposición a sus progenitores. Lo interesante es que, en esos procesos de constitución de sus subjetividades, los tres deben revisar de manera consciente - como en las novelas de Pron y López-o inconsciente — como en la novela de Bruzzone- esos relatos familiares y el resultado de esas revisiones son las novelas que leemos. 


\section{La consolidación de un género}

En El género gauchesco, Ludmer señala que el hecho de que un libro se pueda leer desde otro si bien es lo que nos permite pensar en series siempre variables, es también lo que nos habilita a pensar en la composición de un género. Cuando en los textos resuenan voces de otros textos estamos en presencia de algo que se ha cristalizado, de una experiencia sistematizada en múltiples textos, de un género. En Aparecida de Marta Dillon, pueden leerse los ecos de múltiples relatos de hijos/as de desaparecidos/as. La crónica que hace Dillón sobre el proceso de recuperación de los huesos de su madre cierra una cadena de búsquedas y relatos que ya habían escrito otros/as hijos/as.

En el libro de Dillon está la muchacha muy bella de Julián López en esa fotografía inicial de Marta con su madre en la playa; está la voz institucional de Maco Somigliana del equipo de antropología forense; está la voz de Raquel Robles y esa historia que cuenta sobre la bala de goma que atravesó su brazo en una marcha de H.I.J.o.s. en La Plata y que le sirve a Marta para consolarse pensando que las marcas de bala que aparecen en los huesos de su mamá no duelen porque lo dijo Raquel. Está la sombra de Los Rubios (Carri), no sólo porque la mujer de Dillon es la directora de la película, sino porque la propia Dillon recrea con palabras la escena en la que Albertina Carri toca el timbre de los vecinos de su infancia. En el libro, Marta junto a la antropóloga recorre las calles del partido de San Martín buscando la esquina exacta en la que ocurrió el «falso enfrentamiento» en el que asesinaron a su madre.

Están los ecos de Mi vida después, el psicodrama de Lola Arias, en donde se pone en escena esa enorme montańa de ropa de los padres y los/as protagonistas van «luciéndola» mientras hablan de sus vidas. En Dillon, «la guardarropía revolucionaria» (Nofal 2015) aparece en todo su esplendor en forma de harapos que sobreviven a los fusilamientos: mangas de camisas, retazos de cuellos de remeras, un conjunto de ropa interior negro, las medias cancán, la polera azul con las mangas recortadas que usaba su mamá el día que la asesinaron. A esa historia, la de la polera, se la cuenta una compañera de cautiverio de su madre, quien le dice que para evitar el calor, la mamá de Marta recortó las mangas de su polera y ese mismo gesto tuvo con otros compañeros.

Aquí la épica de los padres está intacta. Dillon enaltece la memoria de su madre, recupera esa cotidianeidad doméstica que estaba borroneada por el tiempo (Amado) y sale como una detective — igual que la princesa montonera y el narrador de la novela de Patricio Pron- a conocer más sobre su mamá, a completar esa imagen. Dillon se inscribe en la genealogía de los H.I.J.O.s. y se posiciona a sí misma como militante de la organización, como activista LGTB y como reconocida periodista. Pero, además, se reinscribe en su propia genealogía familiar como hermana mayor, madre, esposa y abuela. Marta reconstruye su autobiografía a partir de dar cuenta de una descarnada intimidad. Su voz narradora se desnuda, queda puro hueso, como los huesos que encuentra y no deja nada por contar. Se trata de una voz íntima y política que articula el cuerpo de esas otras voces de 
hijos/as de desaparecidos/as y conforma con ellas una voz nacional que conecta al género de los/as hijos/as con la voz de los gauchos del siglo XIX, en tanto ambas suponen mediaciones (Williams I977) de una época que se representa y se crea en los textos a partir del uso de las voces.

Aparecida se presenta como el último de una serie que hilvana todos los textos trabajados en este artículo. Se trata de un texto militante y mutante a la vez, político e inadecuado, un texto que nos permite pensar un género. Mientras $L a$ casa de los conejos (Alcoba) necesitó ser una evidencia excesiva para dar cuenta de esos cuerpos desaparecidos y dejar constancia de la delación del Ingeniero, el texto de Dillon cierra la cadena en tanto la restitución de los restos plantea nuevas preguntas a las tramitaciones posibles sobre el pasado de violencia dictatorial. En Aparecida la pregunta no es dónde están esos desaparecidos o cómo se hace para habitar esa ausencia; sino lo que pasa cuando los huesos son encontrados. ¿Qué pasa con la condición política del desaparecido?, ¿se trata del fin de la historia? ¿es posible saldar ante los restos las cuentas con el pasado? ¿Es Aparecida el fin de la voz de los hijos, tal como sugiere Ludmer sobre La Vuelta del Martín Fierro? Me atrevo a pensar que sí, aunque aún habrá que esperar para saber si el cambio ideológico de las políticas estatales sobre memoria tiene repercusión en las ficciones sobre el pasado dictatorial argentino.

\section{Notas}

1 Militante de H.I.J.o.s. Tucumán, asesinada en diciembre de 2016 por un automovilista en la Ruta $\mathrm{N}^{\circ} 38$, cuando regresaba de una jornada por la memoria en «La Escuelita de Famaillá».

2 Sólo por nombrar algunos, se pueden consultar $E l$ Payador de Leopoldo Lugones (1916) y El discurso criollista en la formación de la Argentina moderna de Adolfo Prieto (1988).

3 Desarrollé algunas hipótesis en torno a la novela argentina contemporánea en mi tesis doctoral, Las voces de la memoria en la novela argentina contemporánea: militantes, testigos e hijoslas de desaparecidos/as (2000-2014), en donde establecí tres series literarias — la de los militantes, los/as hijos/as y los testigos — que atendían a las voces narradoras de cada novela y que me permitieron establecer vinculaciones entre quienes narran en esas ficciones y los/as diferentes actores/as sociales que en el espacio público se disputan diferentes sentidos y versiones sobre cómo armar un relato de la violencia política y la represión estatal en Argentina durante la década de 1970.

${ }^{4}$ Sobre los efectos que produce el género gauchesco en la esfera social en la que emerge, dice Ludmer: «El género, como el ejército, como la ley, sirve ahora para definir la palabra o la voz "gaucho": el género puede sustituir a la ley (que define al gaucho como delincuente) y al ejército (que lo define como patriota), porque define las condiciones de uno y otro, y sus sentidos, en la construcción de su voz. Define los usos posibles de la palabra y con ella los de los cuerpos: dice que es un gaucho, cómo se lo puede dividir en legal o ilegal, bueno y malo, para qué sirve, qué lugares ocupa y esto en la voz misma del gaucho» (33).

${ }^{5}$ En http://momofuku.com.ar/20I4/entrevistas-felix -bruzzone/

6 En http://www.paginar2.com.ar/diario/suplementos/lasi2/I3-7245-20I2-05-I7.html

7 En http://www.revistaenie.clarin.com/escenarios/ teatro/Saturnalia-Julian-Lopez_o_971303235.html.

${ }^{8}$ Enhttp://tiempo.infonews.com/nota/2066I/la-aparicionde-la-novela-mas-que-una-catarsis-fue-una-reparacion 
${ }^{9}$ En http://revistalagranada.com.ar/19-anos-de-h-i-j-o-s/

10 Sobre las narrativas de hijos e hijas, ver Mariela Peller, Adriana Badagnani, Victoria Daona (2013, 2015).

11 En sus últimos trabajos, Nofal sostiene que «inicialmente el testimonio se definió como un género que rechazó las leyes de la representación artística y se imaginó fiel reproductor de lo real, más próximo a la veracidad de la crónica periodística que a los modos retóricos del relato literario. Ante las definiciones estéticas, reivindicó la tradición de una literatura militante emparentada con la tradición política del realismo socialista. La escritura como una acción revolucionaria y la construcción del discurso heroico son dos de las marcas identitarias de la constitución del género. Sin embargo, la escritura testimonial reciente — cuya narrativa más potente Nofal considera que es la obra de Alcoba - va de la narración de las épicas generacionales a las historias de vida en clave menor (Nofal 20I5).

\section{Bibliografía}

alCOBa, laura (2008). La casa de los conejos. Buenos Aires: Edhasa.

amado, ana (2004). "Ordenes de la memoria y desórdenes de la ficción», en Ana Amado y Nora Domínguez, compiladoras. Lazos de familia. Herencias, cuerpos, ficciones. Buenos Aires: Paidós, 45-84.

BADAGNANI, ADRIANA (2013). «La memoria de los pequeños combatientes: Raquel Robles y la narrativa de los hijos de desaparecidos». Oficios terrestres 29. Universidad Nacional de La Plata. BONALDI, PABlo (2006). «Hijos de desaparecidos. Entre la construcción de la política y la construcción de la memoria». Elizabeth Jelin y Diego Sempol, compiladores. (2006). El pasado en el futuro: los movimientos juveniles. Buenos Aires: Siglo XXI, I45-I84.

BrUzzone, félix (2008). Los Topos. Buenos Aires: Mondadori, 2014.

dalmaroni, miguel (2004). La palabra justa. Literatura, crítica y memoria en la Argentina. 1960-2002. Santiago de Chile: RIL/Melusina.

(Dir.) (2009). La investigación literaria. Problemas iniciales de una práctica. Santa Fe: Universidad Nacional del Litoral.

DAONA, VICTORIa (20I3). «Había una vez una casa de los conejos. Una lectura sobre la novela de Laura Alcoba». Aletheia. Revista de la Maestría en Historia y Memoria de la FaHCE 6(3), I-I7. Web. (20I4). «Princesas, combatientes y pilotos. Representación y transmisión en las narrativas de los hijos e hijas de desaparecidos por el terrorismo de estado en Argentina». Telar. Revista del Instituto de Estudios Latinoamericanos de la Facultad de Filosofía y Letras de la UNT 13/14, I66-186.

Dillon, MARTA (20I5). Aparecida. Buenos Aires: Sudamericana.

DRUCAROFF, ELSA (2OII). Los prisioneros de la torre: politica, relatos y jóvenes en la postdictadura.

Buenos Aires: Emecé.

Hassoun, JaQues (1996). Los contrabandistas de la memoria. Buenos Aires: La Flor. JELIN, ELIZABETH (2002). Los trabajos de la memoria. Lima: Instituto de Estudios peruanos, $2 \mathrm{OI2}$. (20I0). "¿Víctimas, familiares y ciudadanos/as? Las luchas por la legitimidad de la palabra», en Emilio Crenzel, coordinador. Los desaparecidos en la Argentina. Memorias, representaciones e ideas (1983-2008). Buenos Aires: Biblos, 227-249.

(20II). «Dilemas actuales: los abusos sexuales como crímenes de lesa humanidad y el respeto a la intimidad». Lucha Armada en la Argentina. Anuario 6, 4-15. 
kossellek, reinhart (1993). Futuro pasado. Para una semántica de los tiempos históricos.

Barcelona: Paidós.

LóPEZ, Julián (2013). Una muchacha muy bella. Buenos Aires: Eterna Cadencia.

LUDMER, JOSEFINA (1988). El género gauchesco. Un tratado sobre la patria. Buenos Aires: Libros

Perfil, 2000.

NOFAL, ROSSANA (20IO). "Desaparecidos, militantes y soldados: de la literatura testimonial a los parte de Guerra», en Emilio Crenzel, coordinador. Los desaparecidos en la Argentina. Memorias, representaciones e ideas (1983-2008). Buenos Aires: Biblos, I6I-I87.

(2015). «Configuraciones metafóricas en la narrativa argentina sobre memorias de dictadura». Revista Kamchatka 6, 835-851.

PELLER, MARIELA (2OIO). «Herederos: fielmente infieles. La generación de los hijos e hijas revisita la militancia armada de los setenta». Actas de las $v$ Jornadas de Trabajo sobre Historia Reciente. Buenos Aires: Universidad Nacional General Sarmiento, I-I8.

perez, mariana eVA (20I2). Diario de una princesa montonera. IIo \% Verdad. Buenos Aires: Capital Intelectual.

PRIVIdera, Nicolás (2009). «Plan de evasión. Presentación de Los Topos de Félix Bruzzone», 20I6. Web.

pron, patricio (20II). El espiritu de mis padres sigue subiendo en la lluvia. Buenos Aires: Mondadori, 2012.

Ricoeur, PaUl (1999). Historia y Narratividad. Barcelona: Paidós.

robles, raquel (2013). Pequeños combatientes. Buenos Aires: Alfaguara.

sarlo, beatriz (2005). Tiempo Pasado. Cultura de la memoria y giro subjetivo. Una discusión.

Buenos Aires: Siglo XxI.

SEMÁN, ERNeSTO (2OII). Soy un bravo piloto de la nueva China. Buenos Aires: Mondadori.

SOSA, CECILIA (2OII). «Queerings Acts of mourning in the aftermath of Argentina's dictatorship:

The mother of Plaza de Mayo and Los Rubios, en Vincent Druliolle y Francesca Lessa, editorxs. The memory of State Terrorism in the Southern Cone: Argentina, Chile and Uruguay.

New York: Palgrave, 63-85.

WILliams, RAYMOND (1977). Marxismo y literatura. Buenos Aires: Las Cuarenta, 2009.

(1994). Sociología de la cultura. Barcelona: Paidós. 